\title{
Gastropod (Otala lactea) shell nanomechanical and structural characterization as a biomonitoring tool for dermal and dietary exposure to a model metal
}

Paul G. Allison ${ }^{2}$, Jennifer M. Seiter ${ }^{2}$, Alfredo Diaz ${ }^{3}$, James H. Lindsay ${ }^{2}$, Robert D.

$$
\text { Moser }{ }^{4} \text {, Ryan V. Tappero }{ }^{5} \text {, and Alan J. Kenned } y^{2}
$$

${ }^{1}$ University of Alabama, Department of Mechanical Engineering, Box 870276, Tuscaloosa, AL 35406, USA

${ }^{2}$ US Army Engineer Research and Development Center, Environmental Laboratory, 3909 Halls Ferry Rd, Vicksburg, MS 39180, USA

${ }^{3}$ University of Puerto Rico at Mayaguez, Department of Mechanical Engineering, 259 Boulevard Alfonso Valdes, Mayaguez, PR 00681, USA

${ }^{4}$ US Army Engineer Research and Development Center, Geotechnical and Structures Laboratory, 3909 Halls Ferry Rd, Vicksburg, MS 39180, USA

${ }^{5}$ National Synchrotron Light Source at Brookhaven National Laboratory, Beamline X27A, Bldg 725, Upton, NY 11973, USA

*Corresponding Author, Email: pallison@eng.ua.edu, Phone: 205-348-9271.

Keywords: Biomonitoring; Gastropod; Nanoindentation; Synchrotron; Heavy Metal; XRay 


\section{Abstract}

Metallic tungsten (W) was initially assumed to be environmentally benign and a green alternative to lead. However, subsequent investigations showed that fishing weights and munitions containing elemental $W$ can fragment and oxidize into complex monomeric and polymeric tungstate $\left(\mathrm{WO}_{4}\right)$ species in the environment; this led to increased solubility and mobility in soils and increased bioaccumulation potential in plant and animal tissues. Here we expand on the results of our previous research, which examined tungsten toxicity, bioaccumulation, and compartmentalization into organisms, and present in this research that the bioaccumulation of $\mathrm{W}$ was related to a greater than $50 \%$ reduction in the mechanical properties of the snail (Otala lactea), based on depth-sensing nanoindentation. Synchrotron-based X-ray fluorescence maps and X-ray diffraction measurements confirm the integration of $W$ in newly formed layers of the shell matrix with the observed changes in shell biomechanical properties, mineralogical composition, and crystal orientation. With further development, this technology could be employed as a biomonitoring tool for historic metals contamination since unlike the more heavily studied bioaccumulation into soft tissue, shell tissue does not actively eliminate contaminants.

\section{Introduction}

Biological uptake of metals into the soft tissue of terrestrial and aquatic animals is a well studied and is commonly used to determine the bioavailability of contaminants in environmental matrices (Bryan and Langston, 1992; Huanxin et al., 2000; Lanno et al., 
2004; Protasowicki et al., 2008). While bioaccumulation is reasonably well understood for soft tissue, less is understood about incorporation of metals bioaccumulated into soft tissue and subsequently compartmentalized into the hard shell. Shell-bearing bivalves (mussels, clams) and gastropod snails are relevant biological models to study the potential for such compartmentalization from soft tissue to the shell. As follow on work to our previous article that reported on the primary bioaccumulation of tungsten (W) into a plant and herbivorous snail (Kennedy et al., 2012), the novel results presented here focused on changes to shell biomechanical properties collocated with $\mathrm{W}$ bioincorporation in the shell. Tungsten was selected as the model contaminant of concern since it was initially of great interest as a green alternative for lead munitions and fishing weights (Clausen and Korte, 2009; Council, 2003; Davitt, 1980; Felt et al., 2011; Koutsospyros et al., 2006; Li and Wang, 1955; Strigul et al., 2005) before it was determined elemental $\mathrm{W}$ oxidizes and then dissolves into diverse monomeric and polymeric species in the environment (Bednar et al., 2009; Butler et al., 2009; Clausen and Korte, 2009; Felt et al., 2011). Additional detail on the military and commercial use, toxicology and bioaccumulation are available (Kennedy et al., 2012). Terrestrial gastropod snails were selected since they directly consume plants known to heavily bioaccumulate W (Johnson et al., 2009; Kennedy et al., 2012), have multiple and unique compartments for bioaccumulation (e.g., liver, mantle, shell) and are a food source for higher level organisms (e.g., birds) that could further mobilize W from the initial site of contamination through trophic transfer. 
Snails acquire calcium from their environment to build and maintain the structure and strength of their $\mathrm{CaCO}_{3}$ based shells. Thus, there is likely a biological uptake pathway for $\mathrm{W}$ and other metals in the environment to bioaccumulate into the soft tissue of snails (Chou et al., 2010; Demina et al., 2012; Gundacker, 2000) via, transfer from the stomach to the hepatopancreas to the mantle; the mantle is the organ used to secrete and build new shell material, thus providing the vector for metal bio-incorporation into the shell (Wagge, 1951).

The shell is made up of three layers; a protective outer layer called the periostracum that consists of protein (predominately glycine), a middle prismatic layer consisting of a chalky $\mathrm{CaCO}_{3}$ (calcite) and an inner nacre layer consisting of hard and smooth $\mathrm{CaCO}_{3}$ (aragonite) (Markich et al., 2002; Meenakshi et al., 1974; Puente et al., 1996; Wagge, 1951). While all three layers are secreted by the mantle, only the lead edge of the mantle secretes the protein needed to construct the periostracum at the opening (aperture) or lead edge of the shell; thus, while mollusks can repair damaged or broken shell or increase the thickness of the nacre (both occur by the same process), they do not repair the periostracum.

Shell repair in gastropods was studied as early as 1709 by Réaumur and by many subsequent zoologists (Da Costa, 1776). Additionally, researchers have reported on the mechanical response of gastropod shells using depth-sensing / instrumented indentation (Yao et al., 2010). The review article by Heinemann (Heinemann et al., 2011) on the structure, properties, and growth of gastropod nacre highlight the mechanical 
characterization performed by tensile, compressive, bending, shear tests and nanoindentation. Heinemann et al. additionally provided insight into the nacreous structure through optical and electron microscopy imaging to identify natural design principles such as the nanoasperities and interlocking mineral platelets, which provide toughening mechanisms in the nacre.

While the physical structure of the mollusk shell has been extensively studied (Marin et al., 2008), little work was performed in the context of contaminant uptake, distribution and mineralization in the shell. Multiple investigations have provided evidence that bivalve and gastropod shells accumulate metal contaminants (Belabed et al., 2013; Fukunaga and Anderson, 2011; Marin et al., 2008; Mostafa et al., 2013; Puente et al., 1996; Siriprom and Limsuwan, 2009; Walsh et al., 1995; Yap et al., 2003; Zhou et al., 2008; Zuykov et al., 2013). However, to these authors' knowledge, this article is the first study to link the presence of a metal contaminant with a change in shell mechanical properties. The objective of this research was to investigate whether $\mathrm{W}$ bioaccumulated by snails from both direct dermal contact with contaminated soil and through consumption of contaminated plant food was integrated into new growth shell material and whether the presence of $\mathrm{W}$ in the shell was co-located with altered shell biomechanical properties.

\section{Materials and Methods}

\subsection{Test Materials and biological exposures}


The spiking of elemental W into soil, direct cabbage (Brassica oleracae) and snail (Otala lactea) exposures to that soil and feeding studies of W-contaminated cabbage to the snail were conducted for 28 days as we previously described (Kennedy et al., 2012). Gastropods were then directly exposed to W-contaminated soil (hereafter referred to as "W-dermal") or through a dietary exposure of W-contaminated cabbage (hereafter referred to as "W-dietary") as previously described for 28 days.

\subsection{Specimen preparation}

Shells from gastropods were initially damaged prior to exposure to the $\mathrm{W}$ contaminated substrate by removing a $1 \mathrm{~cm}^{2}$ section from the outer whorl using a diamond rotary blade to facilitate regeneration. Shells were damaged to facilitate the shell repair mechanism to acquire newly formed shell material in conjunction with the $\mathrm{W}$ exposures described above. After exposure, the outer shell whorl cross-sections of control, W-dermal, and Wdietary samples were mounted in epoxy resin. Once mounted, a step-wise polishing procedure consisting of $15,6,1-\mu \mathrm{m}$ silica particles with a final polish of $50-\mathrm{nm}$ colloidal silica suspension prepared the smooth flat surface necessary for nanoindentation. Between each polishing step, sonication in distilled water for 15 minutes removed any loose particles that would scratch the surface for the subsequent polishing step.

\subsection{Imaging of Shells}

The reflected mode (bright and dark field) of a Zeiss Imager Z1m optical microscope and the backscattered electron detector of a FEI Nova NanoSEM 630 scanning electron microscope (SEM) imaged the shells after nanoindentation. The mosaic feature in the 
optical microscope's software acquired 10 individual images for each whole shell crosssection and then the software reconstructed/stitched the individual images to a single image for each shell. The backscatter detector performed SEM imaging at an accelerating voltage of $10-\mathrm{kV}$ in low-vacuum mode while the chamber moisture content was held at $0.1 \mathrm{mbar}$ so the nonconductive shells would not charge from the electron beam.

\subsection{Synchrotron}

Synchrotron-based micro-X-ray Diffraction ( $\mu$-XRD) was performed at beamline X27A at the National Synchrotron Light Source at Brookhaven National Laboratory in Upton, NY. XRD data was collected at $0.7093 \lambda$ with aluminum oxide $\left(\alpha-\mathrm{Al}_{2} \mathrm{O}_{3}\right)$ and silver behenate $\left(\mathrm{AgC}_{22} \mathrm{H}_{43} \mathrm{O}_{2}\right)$ as calibration standards. The beam size on the sample was approximately $7 \mu \mathrm{m}$ x $10 \mu \mathrm{m}$ using Rh-coated Kirkpatrick-Baez focusing optics. X-rays were selected using a water-cooled channel-cut $\mathrm{Si}(111)$ monochromator. XRF data were collected using a Canberra 13-element Ge array solid-state detector. XRD data was fit using Fit2D and Match! software packages.

\subsection{Nanomechanical Characterization}

Once shell repair of the damaged area occurred for the samples in the individual environments (within 28-days following initial damage), instrumented indentation (i.e., nanoindentation) was performed according to the procedure described by the research team (Allison et al., 2015; P G Allison et al., 2013; P. G. Allison et al., 2013; P.G. Allison et al., 2014, 2012; Paul G Allison et al., 2014; Chandler et al., 2014; Moser et al., 2013) to probe three different zones of each shell: (1) the original shell material before 
damage, (2) the regrowth of the damaged area, and (3) new growth after damage that is directly below the old growth (see Figure 1).

An Agilent Technologies G200 nanoindenter with a pyramid shaped diamond Berkovich indenter with tip radius of approximately $20 \mathrm{~nm}$ performed the indentations. The nanoindenter performed a $2^{\text {nd }}$ order area function calibration on a fused silica reference material prior to each specimen. The load-controlled nanoindentation measurements performed tests with a maximum load of $50-\mathrm{mN}$ so the interaction volume would be able to capture representative changes in the microstructure (i.e. porosity, changes in crystalline orientation). An indent spacing of 50- $\mu \mathrm{m}$ ensured that indents were spaced at least 30 times their maximum depth so only the interaction volume of interest was probed without the influence of the composite mechanical response of the adjacent areas or the previous indents affecting the nanomechanical response. A total of 30 indents were performed on the three different zones for each shell cross-section, which were a minimum of $50-\mu \mathrm{m}$ to obtain a robust data set. A hold segment in air corrected for thermal drift by waiting until the thermal drift was less than $0.5 \mathrm{~nm}-\mathrm{s}^{-1}$ before testing initiated. The nanoindenter software used the Oliver and Pharr (Oliver and Pharr, 2011) method to calculate the nanoindentation modulus and hardness, which uses the initial unloading portion of the load-displacement curve to determine contact stiffness.

The hardness, $H$, and contact stiffness, $S$, expressions used are:

$$
H=\frac{P_{\max }}{A}
$$




$$
S=\beta \frac{2}{\sqrt{\pi}} E_{f} \sqrt{A}
$$

where $P_{\max }$ is the maximum load during indentation, $A$ is the contact area, $\beta$ is a dimensionless correction factor $(\beta=1.034$ for Berkovich indenter tips), the effective elastic modulus, $E_{f}$, incorporates the elastic displacement occurring for both the specimen and the indenter as

$$
\frac{1}{E_{f}}=\frac{1-v^{2}}{E}+\frac{1-v_{i}^{2}}{E_{i}}
$$

with the elastic modulus, $E$, and Poisson's ratio, $u$, of the specimen. Where $E_{i}$ and $v_{\mathrm{i}}$ are the elastic modulus and Poisson's ratio of the indenter, respectively.

\subsection{Statistical Analysis}

Statistical analyses were performed by 2 -way analysis of variance (factors: exposure X shell location) using SigmaStat ${ }^{\circledR}$ (SPSS, Chicago IL) software. Data were transformed by squaring to meet the assumptions of normality. Data normality and homogeneity were determined by the Kolmogorov-Smirnov test and Levene's Test, respectively. Since an unequal number of experimental replicates $(\mathrm{N})$ were used $(\mathrm{N}=8$ to 15$)$, the two-tailed Bonferroni t-test (all pairwise multiple comparisons) was applied to determine significant endpoint reductions. All statistically significance was determined at the $\alpha=0.05$ level.

\section{Results and Discussion}

\subsection{Characterization of Structure}




\subsubsection{Optical and SEM Imaging}

The optical and SEM images of Figure 1 provide the morphology characteristics for old and new growth locations on each specimen. In the control samples not exposed to W, both the new growth and old growth appeared to be dense with a similar oriented structure, which is consistent with the structures reported by Meenakshi et al. (Meenakshi et al., 1974) for $O$. lactea shells. In samples that were exposed to $\mathrm{W}$, the microstructure in the new growth exhibited increased porosity and limited amounts of similar orientation, both of which are likely associated with the reduction in elastic modulus (P. G. Allison et al., 2012) and hardness measured by nanoindentation.

\subsubsection{Synchrotron Analysis}

Previous research has also suggested that the crystallographic structure of biomineralized phases can shift in regrowth areas when compared with old growth in gastropod shells. In order to investigate this phenomena, 2D XRD patterns were converted to onedimensional (1D) XRD plots of intensity versus angle to make comparisons between the biomineral phases present in old growth shell containing the regrowth layer as seen in Figure $1 b$, and isolated regrowth areas (Figure 2) from the gastropod shells exposed to W-containing soils.

The 2D XRD patterns of the dermal old growth (Figure 2a) indicated a high degree of preferential orientation. The 1D calculated XRD plot of the old growth indicated that it was essentially $100 \%$ composed of the aragonite polymorph of calcium carbonate. Both of these results are consistent with the typical biomineralized structure present in 
gastropod shells. However, in the new growth when $\mathrm{W}$ was present, a significant difference in both orientation and crystallographic structure was observed. From the 2D XRD patterns, it is clear that the crystal orientation is much more random than in the old growth (i.e., uniform diffracted X-ray intensities in all orientations in the new growth vs. the non-uniform diffracted X-ray intensities in the old growth). The 1D calculated XRD plot for the W-exposed new growth also indicated that both calcite and aragonite polymorphs of calcium carbonate were present in the new growth. The new growth showed evidence of multiple sites of single crystal diffraction, which likely corresponds to the large randomly oriented crystals observed in the SEM micrographs (Perez-Huerta et al., 2011). The dietary sample displayed similar results; however, for brevity of this article they are not included. In addition, there may be many crystal orientations present within the beam footprint in the new growth sample. All of these results suggest the loss of control over crystal structure and orientation during biomineralization when W was present. The presence of $\mathrm{W}$ in the $\mathrm{W}$-dermal old and new growth sections of the shell used for Figure 2 is confirmed in the $2 \mathrm{D} \mu$-X-ray fluorescence maps and their correlating fluorescence emission spectra in Figure 3.

Figure 3 shows there is relatively more $\mathrm{W}$ in the new growth than the old growth regions of the shell, and that $\mathrm{W}$ is incorporated throughout the new growth material. The dietary XRF results showed similar results as the dermal data presented in Figure 3, but was omitted for conciseness of the article. XRF spectra in the new growth also identified Mn, $\mathrm{Fe}, \mathrm{Cu}$, and $\mathrm{Zn}$ in addition to the presence of $\mathrm{W}$. This suggests that the repaired shell material is capable of incorporating a wide variety of elements during repair, which 
would allow the shell to be a diverse biomonitoring tool for multiple contaminants of concern.

\subsection{Nanomechanical Properties}

The indentation modulus and hardness are plotted in Figure $4 \mathrm{a}$ and $4 \mathrm{~b}$, respectively, for the control, W-dietary, and W-dermal exposed specimens. The mechanical properties of the control specimen zones including original and new growth (no W exposure) and the original shell zones (prior to $\mathrm{W}$ exposure for both the $\mathrm{W}$-dietary and $\mathrm{W}$-dermal snails) for all the specimens modulus values $(\mathrm{E}=60-97 \mathrm{GPa})$ reported in Figure $4 \mathrm{a}$ were consistent with nanoindentation data for gastropod shells reported in the open literature $(E=60-120$ GPa) (Barthelat et al., 2006; Li et al., 2004; Pérez-Huerta et al., 2007). The lowest average modulus reported was for the $\mathrm{W}$-dermal exposed shell at both the repair site and new growth under old growth site, but the W-dermal results also had the largest data scatter among the control, W-dietary, and W-dermal specimens.

Two-way ANOVA of pooled data for all shell locations (original, new growth, regenerated at the repair site) indicated statistically significantly higher modulus ( $\mathrm{p}<$ 0.001) for the control (unexposed) shell relative to the dermal and dietary W-exposed shell. There was no significant difference for pooled new growth and repair site modulus data. When all data from the dermal and dietary exposed shells were pooled, the original shell had significantly higher modulus $(\mathrm{p}<0.001)$ than the new growth under old shell and regenerated shell at the repair site shell. The pooled repair site shell also had significantly higher $(\mathrm{p}<0.001)$ modulus than the new growth under old shell. 
The unexposed original shell and regenerated shell at the repair site had slightly but significantly $(\mathrm{p}=0.021)$ higher modulus than the new growth shell under the old shell (Figure 4). The original shell material had significantly higher modulus in the unexposed and dietary exposed treatments relative to the dermal exposure. The unexposed shell consistently had significantly and substantially higher modulus than the W-exposed shell, regardless of whether the exposure to $\mathrm{W}$ was dermal $(\mathrm{p}<0.001)$ or dietary $(\mathrm{p}<0.001)$ and regardless of whether the comparison was for new shell growth under the old shell (p $<0.001)$ or for regenerated shell at the repair site $(\mathrm{p}<0.001)$.

The analysis of the control sample actually reported a slightly higher average hardness for the new growth material at the repair site over the original shell hardness, which is attributed to the uncertainty in the physical structure of the shells. The W-dietary exhibited the lowest average hardness for the new growth at the repair site while the Wdermal displayed the lowest average hardness for the new growth under the old original shell. The W-dermal sample displayed more scatter in the hardness data for both new growth sites, as was observed for the modulus data likely resulting from a large variability in the material's structure.

Two-way ANOVA of pooled data for all shell locations (original, new growth, repair site) indicated that the control, new growth under old shell and regenerated shell at the repair site were all statistically significantly different from one another $(\mathrm{p}<0.001)$. When data from all exposure types (unexposed, dermal, dietary) were pooled, all shell 
areas (original, new growth under old shell, regenerated shell at repair site) had significantly different hardness values from one another $(\mathrm{p} \leq 0.015)$.

The unexposed original shell and regenerated shell at the repair site had slightly but significantly $(\mathrm{p}=0.011)$ higher hardness than the new growth shell under the old shell (Figure 4). The original shell material had significantly different hardness values between the control, dermal and dietary exposures $(\mathrm{p} \leq 0.006)$. The unexposed shell consistently had significantly higher hardness than the W-exposed shell, regardless of whether the exposure to $\mathrm{W}$ was dermal $(\mathrm{p}<0.001)$ or dietary $(\mathrm{p}<0.001)$ and regardless of whether the comparison was for new shell growth under the old shell $(p<0.001)$ or for regenerated shell at the repair site $(\mathrm{p}<0.001)$.

With the control samples old growth and new growth mechanical properties being consistent with published data, the percent differences between the control sample properties and the dietary and dermal sample properties are compared in Figure 5.

Modulus comparison between the new growth for the control sample and the dietary and dermal samples in Figure 5a exhibited between a 50-70\% difference. While the hardness results plotted in Figure $4 \mathrm{~b}$ correlate to over a $60 \%$ reduction in average hardness for the $\mathrm{W}$-dietary and W-dermal new growth sites from the original shell material according to Figure 5b. 
The exposure and subsequent bioaccumulation of $\mathrm{W}$ has a substantial impact (reduction of over $50 \%$ ) of the mechanical properties of the new growth areas of the $\mathrm{W}$-exposed samples relative to the control sample and suggests an adverse impact on snail viability due to health impacts and diminished protection due to weakened shell. An explanation of this reduction in mechanical properties may be attributed to the inability of the mineral platelets to transport a large portion of the applied load since the mineral platelets are not orderly embedded in the organic matrix as observed by Gao (Gao et al., 2003) for traditional shell structures such as the non-W exposed shell areas. Alternatively, W accumulated in the snails' organs may result in a health impact that indirectly reduced their ability to generate strong shell.

\section{Conclusions}

Nanomechanical experiments using instrumented indentation techniques when combined with other forms of micro- and nano-structural characterization clearly showed that the biomineralization process was affected by the presence of $\mathrm{W}$. This includes a reduced ability to control crystal structures (i.e., controlled formation of specific polymorphs of $\mathrm{CaCO}_{3}$ including aragonite and calcite) and crystal orientation in a traditional nacreous structure. The study also demonstrated the utility of a combined approach to characterize the structure-property relationships of biomineralized structures in gastropod shells. Remarkably, a similar decrease in mechanical properties for both the dermal and dietary contaminated samples suggest further investigations of the bioaccumulation mechanisms require additional analysis to identify if the mechanical property decreases may be attributed to similar bioaccumulation mechanisms for both exposures. Future work is 
comparing the tissue bioaccumulation kinetics of snails that were dermally and dietarily exposed to W. Further exploration and quantification of the intrinsic mechanisms for Wexposure decreasing the mechanical response of the material is also planned; however, the current research highlights the usefulness of gastropod shells as a potential baseline biomonitoring tool for historic levels of metal contamination. Simple mechanical testing consisting of techniques such as depth sensing indentation may be useful screening tools for assessing biomonitors that can be supplemented with other quantitative micro- and nano-structural characterization techniques to identify contaminants and their effects as demonstrated in the work by Kennedy (Kennedy et al., 2012).

\section{Acknowledgements}

This work was funded by the Army Environmental Quality Technology Basic Research Program (US Army Engineer Research and Development Center, Dr. Elizabeth Ferguson, Technical Director). Portions of this work were performed at Beamline X27A, National Synchrotron Light Source (NSLS), Brookhaven National Laboratory. X27A is supported in part by the U.S. Department of Energy (DOE) - Geosciences (DE-FG02-92ER14244 to The University of Chicago - CARS). Use of the NSLS was supported by the DOE, Office of Science, Office of Basic Energy Sciences, under Contract No. DE-AC02-98CH10886. Permission to publish granted by Director of the Geotechnical and Structures Laboratory.

\section{References}

Allison, P.G., Chandler, M.Q., Rodriguez, R.I., Williams, B.A., Moser, R.D., Weiss, C.A., Poda, A.R., Lafferty, B.J., Kennedy, A.J., Seiter, J.M., Hodo, W.D., Cook, 
R.F., 2013. Mechanical properties and structure of the biological multilayered material system, Atractosteus spatula scales. Acta Biomater. 9, 5289-96. doi:10.1016/j.actbio.2012.11.005

Allison, P.G., Deang, J.F., Diaz, A.J., Poda, A.R., Hoover, J.J., Horstemeyer, M.F., Perkins, E.J., Hoover, J.J., Deang, J.F., Diaz, A.J., Poda, A.R., Hoover, J.J., Horstemeyer, M.F., Perkins, E.J., 2013. Characterization of paddlefish (Polyodon spathula) rostrum stellate bones. Bioinsp, Biomimet and Nanobiomater 3, 63-68. doi:10.1680/bbn.13.00024

Allison, P.G., Horstemeyer, M.F., Brown, H.R., 2012. Modulus Dependence on Large Scale Porosity of Powder Metallurgy Steel. J Mater Eng Perf 21, 1422-1425. doi:10.1007/s11665-011-0001-6

Allison, P.G., Moser, R.D., Schirer, J.P., Martens, R.., Jordon, J.B., Chandler, M.Q., 2014. In-situ nanomechanical studies of deformation and damage mechanisms in nanocomposites monitored using scanning electron microscopy. Mater. Lett. 131, 313-316. doi:10.1016/j.matlet.2014.05.196

Allison, P.G., Moser, R.D., Weiss, C.A., Malone, P.G., Morefield, S.W., 2012. Nanomechanical and chemical characterization of the interface between concrete, glass-ceramic bonding enamel and reinforcing steel. Constr. Build. Mater. 37, 638644. doi:10.1016/j.conbuildmat.2012.07.066

Allison, P.G., Rodriguez, R.I., Moser, R.D., Williams, B.A., Poda, A.R., Seiter, J.M., Lafferty, B.J., Chandler, M.Q., Kennedy, A.J., Chandler, M.Q., 2014. 
Characterization of multi-layered fish scales (Atractosteus spatula) using nanoindentation, X-ray CT, FTIR, and SEM. J Video Exper e51535-e51535. doi:10.3791/51535

Allison, P.G., Weiss, C. a., Moser, R.D., Diaz, a. J., Rivera, O.G., Holton, S.S., 2015. Nanoindentation and SEM/EDX Characterization of the Geopolymer-to-Steel Interfacial Transition Zone for a Reactive Porcelain Enamel Coating. Compos. Part B Eng. doi:10.1016/j.compositesb.2015.03.011

Barthelat, F., Li, C., Comi, C., Espinosa, H., 2006. Mechanical properties of nacre constituents and their impact on mechanical performance. J. Mater. Res. 1977-1986.

Bednar, A.J., Kirgan, R.A., Johnson, D.R., Russell, A.L., Hayes, C.A., McGrath, C.J., 2009. Polytungstate analysis by SEC-ICP-MS and direct-infusion ESI-MS. L. Contam. Reclam. 17, 129-137. doi:10.2462/09670513.929

Belabed, B.E., Laffray, X., Dhib, A., Fertouna-Belakhal, M., Turki, S., Aleya, L., 2013. Factors contributing to heavy metal accumulation in sediments and in the intertidal mussel Perna perna in the Gulf of Annaba (Algeria). Mar. Pollut. Bull. 74, 477-489. doi:10.1016/j.marpolbul.2013.06.004

Bryan, G.W., Langston, W.J., 1992. Bioavailability, accumulation and effects of heavy metals in sediments with special reference to United Kingdom estuaries: a review. Environ. Pollut. 76, 89-131. doi:10.1016/0269-7491(92)90099-V 
Butler, A.D., Medina, V.F., Larson, S., Nestler, C., 2009. Uptake of lead and tungsten in Cypersu esculentus in a small-arms range simulation. L. Contam. Reclaim. 17, 153159.

Chandler, M.Q., Allison, P.G., Rodriguez, R.I., Moser, R.D., Kennedy, A.J., 2014. Finite element modeling of multilayered structures of fish scales. J. Mech. Behav. Biomed. Mater. 40C, 375-389. doi:10.1016/j.jmbbm.2014.09.013

Chou, J., Clement, G., Bursavich, B., Elbers, D., Cao, B., Zhou, W., 2010. Rapid detection of toxic metals in non-crushed oyster shells by portable X-ray fluorescence spectrometry. Environ. Pollut. 158, 2230-4. doi:10.1016/j.envpol.2010.02.015

Clausen, J.L., Korte, N., 2009. Environmental fate of tungsten from military use. Sci. Total Environ. 407, 2887-2893.

Council, R. prepared by the I.T.\& R. (Ed.), 2003. Characterization and remediation of soils at closed small arms firing ranges. Interstate Technology \& Regulatory Council, Washington, D.C.

Da Costa, E.M., 1776. Elements of conchology: or, an introduction to the knowledge of shells.

Davitt, R.P., 1980. A comparison of the advantages and disadvantages of depleted uranium and tungsten alloy as penetrator materials. U.S. Army Armament Research and Development Command, Dover. 
Demina, L.L., Galkin, S. V., Dara, O.M., 2012. Trace metal bioaccumulation in the shells of mussels and clams at deep-sea hydrothermal vent fields. Geochemistry Int. 50, 133-147. doi:10.1134/S0016702911120056

Felt, D., Larson, S., Griggs, C., Nestler, C., Wynter, M., 2011. Relationship of surface changes to metal leaching from tunsten composite shot exposed to three different soil types. Chemosphere 83, 955-962.

Fukunaga, A., Anderson, M.J., 2011. Bioaccumulation of copper, lead and zinc by the bivalves Macomona liliana and Austrovenus stutchburyi. J. Exp. Mar. Bio. Ecol. 396, 244-252. doi:10.1016/j.jembe.2010.10.029

Gao, H., Ji, B., Jager, I.L., Arzt, E., Fratzl, P., 2003. Materials become insensitive to flaws at nanoscale: lessons from nature. Proc. Natl. Acad. Sci. U. S. A. 100, 5597600. doi:10.1073/pnas.0631609100

Gundacker, C., 2000. Comparison of heavy metal bioaccumulation in freshwater molluscs of urban river habitats in Vienna. Environ. Pollut. 110, 61-71. doi:10.1016/S0269-7491(99)00286-9

Heinemann, F., Launspach, M., Gries, K., Fritz, M., 2011. Gastropod nacre: structure, properties and growth - biological, chemical and physical basics. Biophys. Chem. $126-153$. 
Huanxin, W., Lejun, Z., Presley, B.J., 2000. Bioaccumulation of heavy metals in oyster (Crassostrea virginica) tissue and shell. Environ. Geol. 39, 1216-1226. doi:10.1007/s002540000110

Johnson, D.R., Inouye, L.S., Bednar, A.J., Clarke, J.U., Winfield, L.E., Boyd, R.E., Ang, C.Y., Goss, J., 2009. Tungsten bioavailability and toxicity in sunflowers (Helianthus annuиs). L. Contam. Reclam. 17, 141-151. doi:10.2462/09670513.939

Kennedy, A.J., Johnson, D.R., Seiter, J.M., Lindsay, J.H., Boyd, R.E., Bednar, A.J., Allison, P.G., 2012. Tungsten toxicity, bioaccumulation, and compartmentalization into organisms representing two trophic levels. Environ. Sci. Technol. 46, 9646-52. doi:10.1021/es300606x

Koutsospyros, A., Braida, W., Christiodoulatos, C., Dermata, D., Strigul, N., 2006. A review of tungsten: from environmental obscurity to scrutiny. J. Hazard. Mater. 136, $1-19$.

Lanno, R., Wells, J., Conder, J., Bradham, K., Basta, N., 2004. The bioavailability of chemicals in soil for earthworms. Ecotoxicol. Environ. Saf. 57, 39-47. doi:10.1016/j.ecoenv.2003.08.014

Li, K.C., Wang, Y.U., 1955. Tungsten: its history, geology, ore-dressing, metallurgy, chemistry, analysis, applications, and economics. Reinhold, New York. 
Li, X., Chang, W.-C., Chao, Y.J., Wang, R., Chang, M., 2004. Nanoscale Structural and Mechanical Characterization of a Natural Nanocomposite Material: The Shell of Red Abalone. Nano Lett. 4, 613-617. doi:10.1021/n1049962k

Marin, F., Luquet, G., Marie, B., Medakovic, D., 2008. Molluscan shell proteins: primary structure, origin, and evolution. Curr. Top. Dev. Biol. 80, 209-76. doi:10.1016/S0070-2153(07)80006-8

Markich, S.J., Jeffree, R.A., Burke, P.T., 2002. Freshwater Bivalve Shells as Archival Indicators of Metal Pollution from a Copper,àíUranium Mine in Tropical Northern Australia. Environ. Sci. Technol. 36, 821-832. doi:10.1021/es011066c

Meenakshi, V.R., Donnay, G., Blackwelder, P.L., Wilbur, K.M., 1974. The influence of sustrata on calcification patterns in molluscan shell. Calc. Tiss. Res. 15, 31-44.

Moser, R.D., Allison, P.G., Chandler, M.Q., 2013. Characterization of Impact Damage in Ultra-High Performance Concrete Using Spatially Correlated Nanoindentation/SEM/EDX. J. Mater. Eng. Perform. 22, 3902-3908. doi:10.1007/s11665-013-0668-y

Mostafa, O.M.S., Mossa, a.-T.H., El Einin, H.M. a., 2013. Heavy metal concentrations in the freshwater snail Biomphalaria alexandrina uninfected or infected with cercariae of Schistosoma mansoni and/or Echinostoma liei in Egypt: the potential use of this snail as a bioindicator of pollution. J. Helminthol. 88, 411-416.

doi:10.1017/S0022149X13000357 
Oliver, W.C., Pharr, G.M., 2011. Measurement of hardness and elastic modulus by instrumented indentation: Advances in understanding and refinements to methodology. J. Mater. Res. 15, 1, 3-20.

Pérez-Huerta, A., Cusack, M., Zhu, W., England, J., Hughes, J., 2007. Material properties of brachiopod shell ultrastructure by nanoindentation. J. R. Soc. Interface 4, 33-9. doi:10.1098/rsif.2006.0150

Perez-Huerta, A., Dauphin, Y., Cuif, J.P., Cusack, M., 2011. High resolution electron backscatter diffraction (EBSD) data from calcite biominerals in recent gastropod shells. Micron 42, 246-251. doi:http://dx.doi.org/10.1016/j.micron.2010.11.003

Protasowicki, M., Dural, M., Jaremek, J., 2008. Trace metals in the shells of blue mussels (Mytilus edulis) from the Poland coast of Baltic sea. Environ. Monit. Assess. 141, 329-37. doi:10.1007/s10661-007-9899-4

Puente, X., Villares, R., Carral, E., Carballeira, A., 1996. Nacreous shell of Mytilus galloprovincialis as a biomonitor of heavy metal pollution in Galiza (NW Spain). Sci. Total Environ. 183, 205-211. doi:10.1016/0048-9697(96)05066-8

Siriprom, W., Limsuwan, P., 2009. A biomonitoring study: Trace metals in Amusium pleuronectes shell from the coastal area of Chon Buri province. Kasetsart J. - Nat. Sci. 43, 141-145.

Strigul, N., Koutsospyros, A., Arienti, P., Christiodoulatos, C., Dermatas, D., Braida, W., 2005. Effect of tungsten on environmental systems. Chemosphere 61, 248-258. 
Wagge, L.E., 1951. The Activity of Amoebocytes and of Alkaline Phosphatases during the Regeneration of the Shell in the Snail, Helix aspersa. Q. J. Microsc. Sci. s3-92, $307-321$.

Walsh, K., Dunstan, R.H., Murdoch, R.N., 1995. Differential bioaccumulation of heavy metals and organopollutants in the soft tissue and shell of the marine Gastropod, Austrocochlea constricta. Arch. Environ. Contam. Toxicol. 28, 35-39. doi:10.1007/BF00213966

Yao, H., Dao, M., Imholt, T., Huang, J., Wheeler, K., Bonilla, A., Suresh, S., Ortiz, C., 2010. Protection mechanisms of the iron-plated armor of a deep-sea hydrothermal vent gastropod. Proc. Natl. Acad. Sci. U. S. A. 107, 987-992. doi:10.1073/pnas.0912988107

Yap, C.K., Ismail, a., Tan, S.G., Abdul Rahim, I., 2003. Can the shell of the green-lipped mussel Perna viridis from the west coast of Peninsular Malaysia be a potential biomonitoring material for $\mathrm{Cd}, \mathrm{Pb}$ and $\mathrm{Zn}$ ? Estuar. Coast. Shelf Sci. 57, 623-630. doi:10.1016/S0272-7714(02)00401-8

Zhou, Q., Zhang, J., Fu, J., Shi, J., Jiang, G., 2008. Biomonitoring: An appealing tool for assessment of metal pollution in the aquatic ecosystem. Anal. Chim. Acta 606, 135150. doi:10.1016/j.aca.2007.11.018

Zuykov, M., Pelletier, E., Harper, D. a T., 2013. Bivalve mollusks in metal pollution studies: From bioaccumulation to biomonitoring. Chemosphere 93, 201-208. doi:10.1016/j.chemosphere.2013.05.001 


\section{List of Figures}
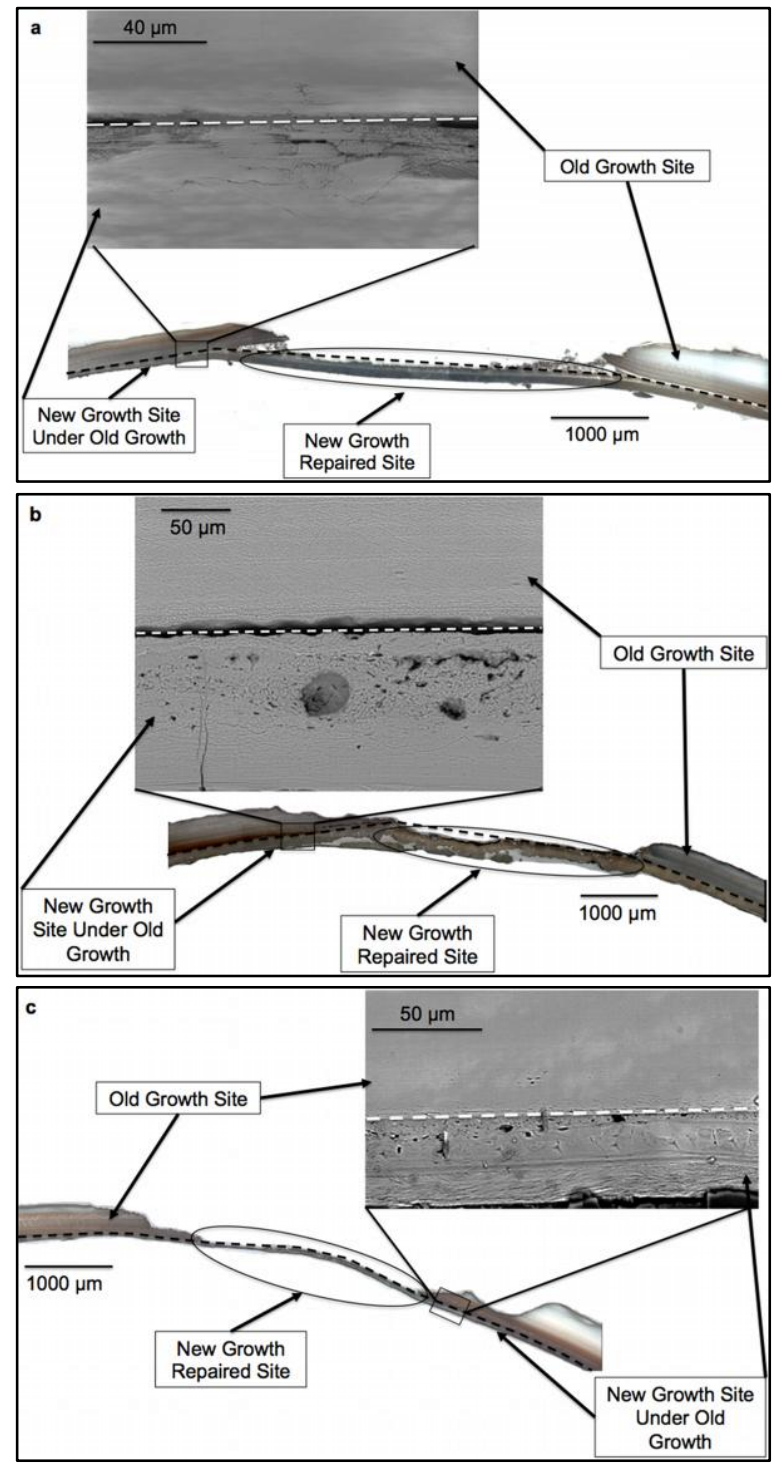

Figure 1. (a) Control specimen with old growth shell (no W contamination) and new growth shell areas (no W contamination). (b) W-dermal exposure specimen with old growth shell (no W contamination) and new growth shell areas (W contamination). (c) W-dietary exposed specimen with old growth shell (no W contamination) and new growth shell areas (W contamination). 

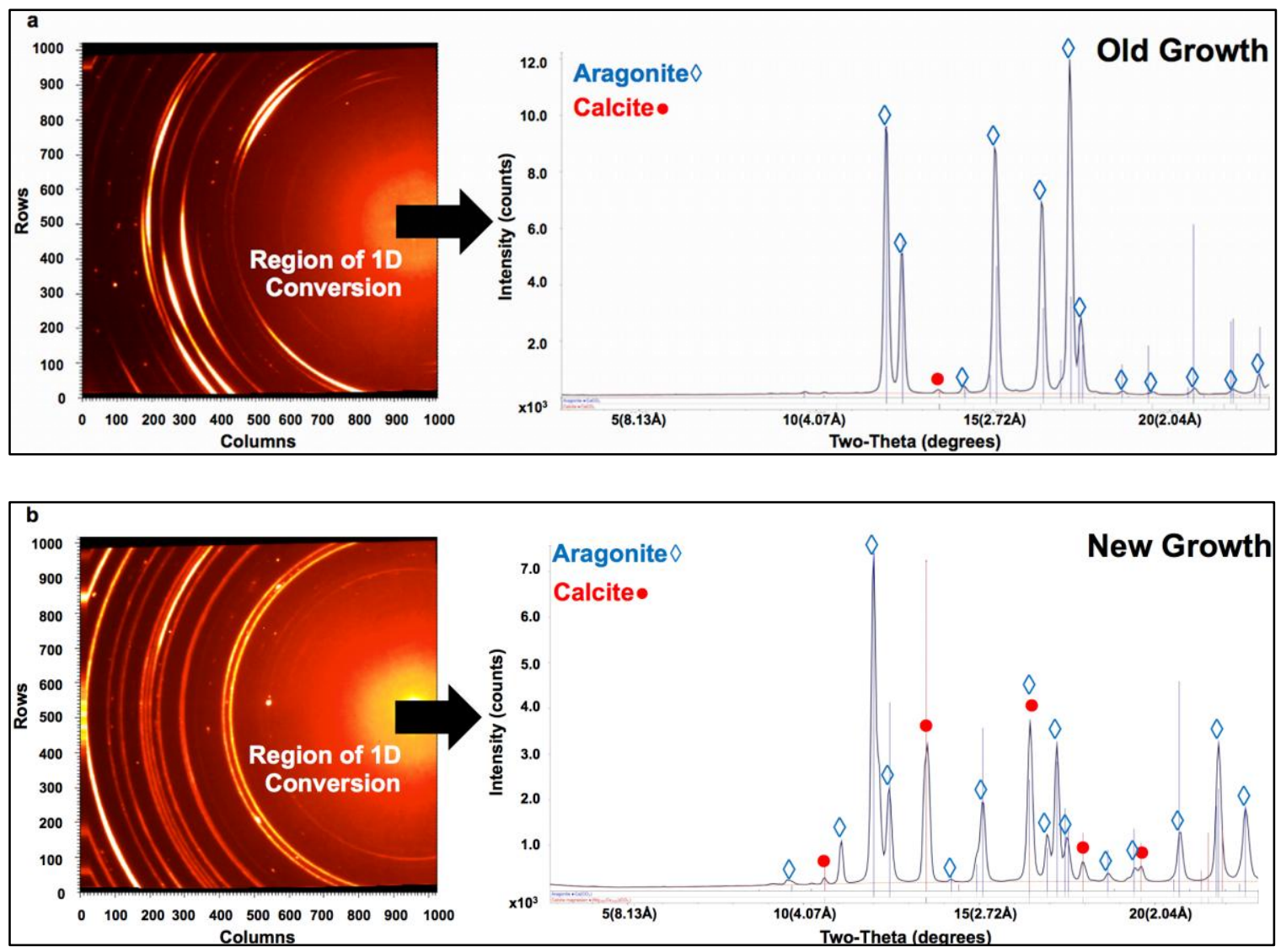

Figure 2. X-ray diffraction (XRD) pattern of (a) old growth and (b) new growth for the dermal exposed shell showing large differences in crystallographic orientation and structure. 

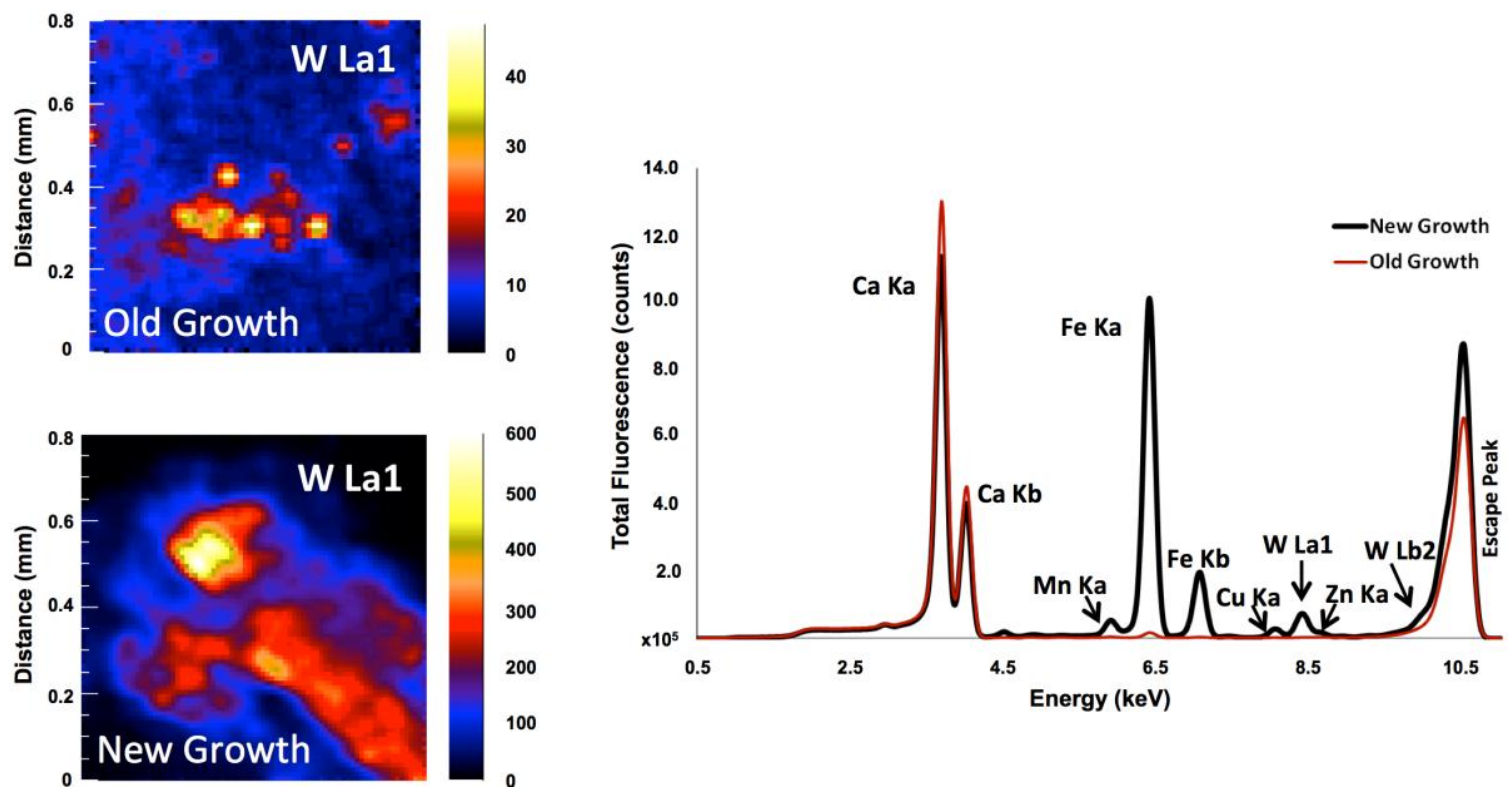

Figure 3. $\mu$-X-ray Fluorescence (XRF) images and XRF emission spectra confirm the increased presence of $\mathrm{W}$ in the new-growth shell material. 

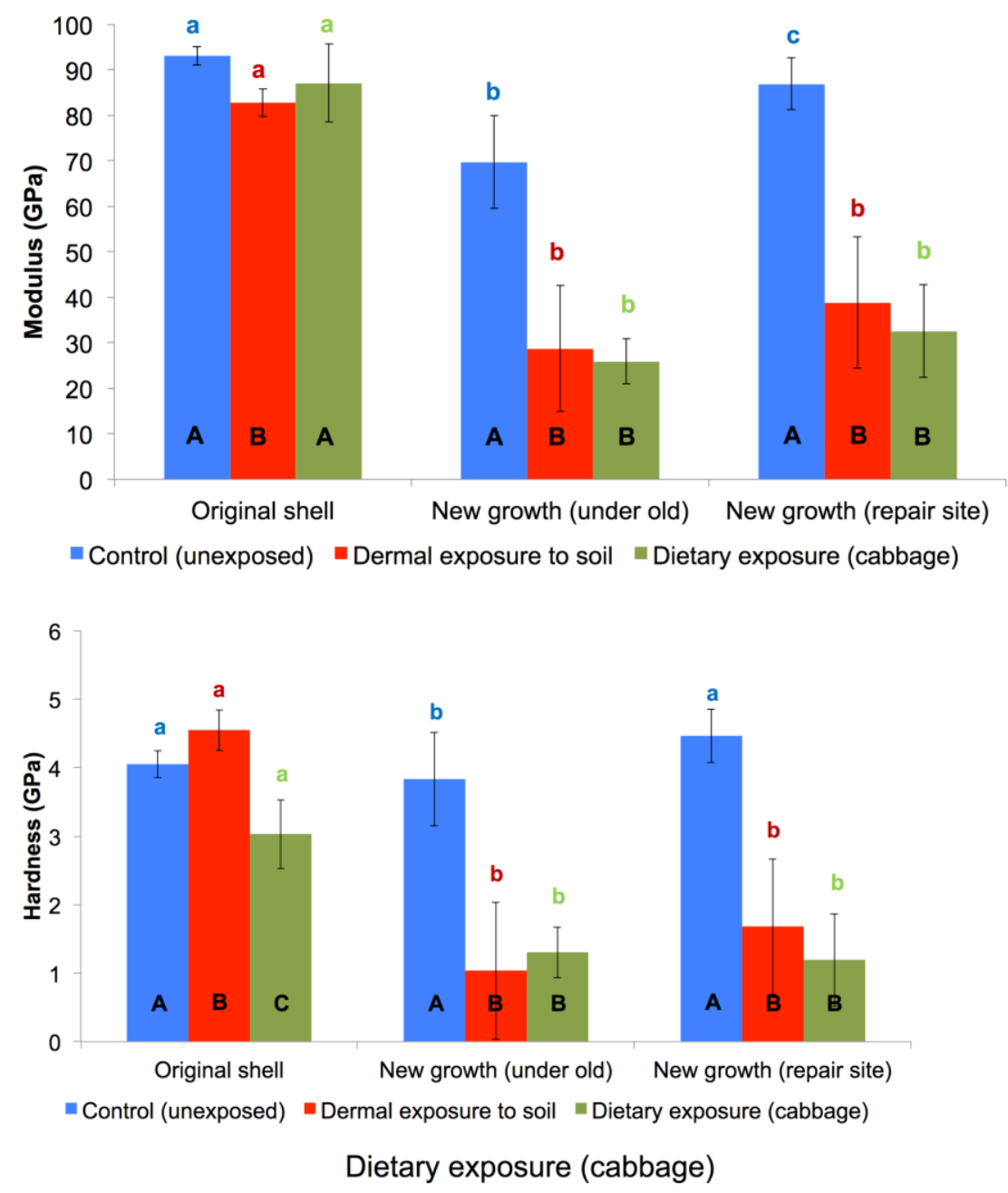

Figure 4. Summary of modulus (a) and hardness (b) comparisons of tungsten exposed and unexposed shell at different locations (old growth, new growth under old shell, and regenerated shell at the repair site). Error bars represent one standard deviation from the mean. Data not sharing the same letter designation were determined statistically significant by 2-way ANOVA. Capital letters indicate individual comparisons within the original shell, within the new growth shell under the old shell, and within regenerated shell at the repair site. Colored lowercase letters are for statistical comparisons within the control (blue), within the dermal exposed specimens (red) and within the dietary exposed specimens (green). 


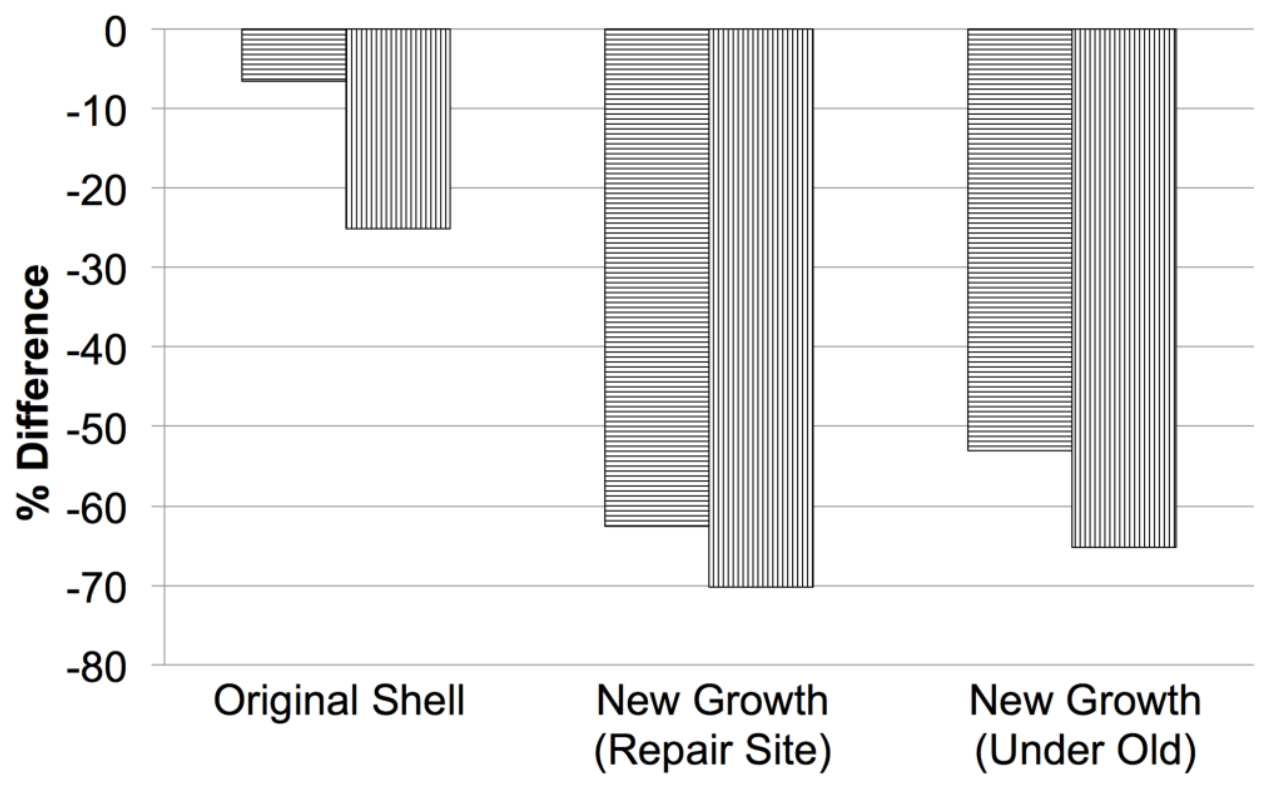

Dietary exposure (cabbage) Dermal exposure to soil

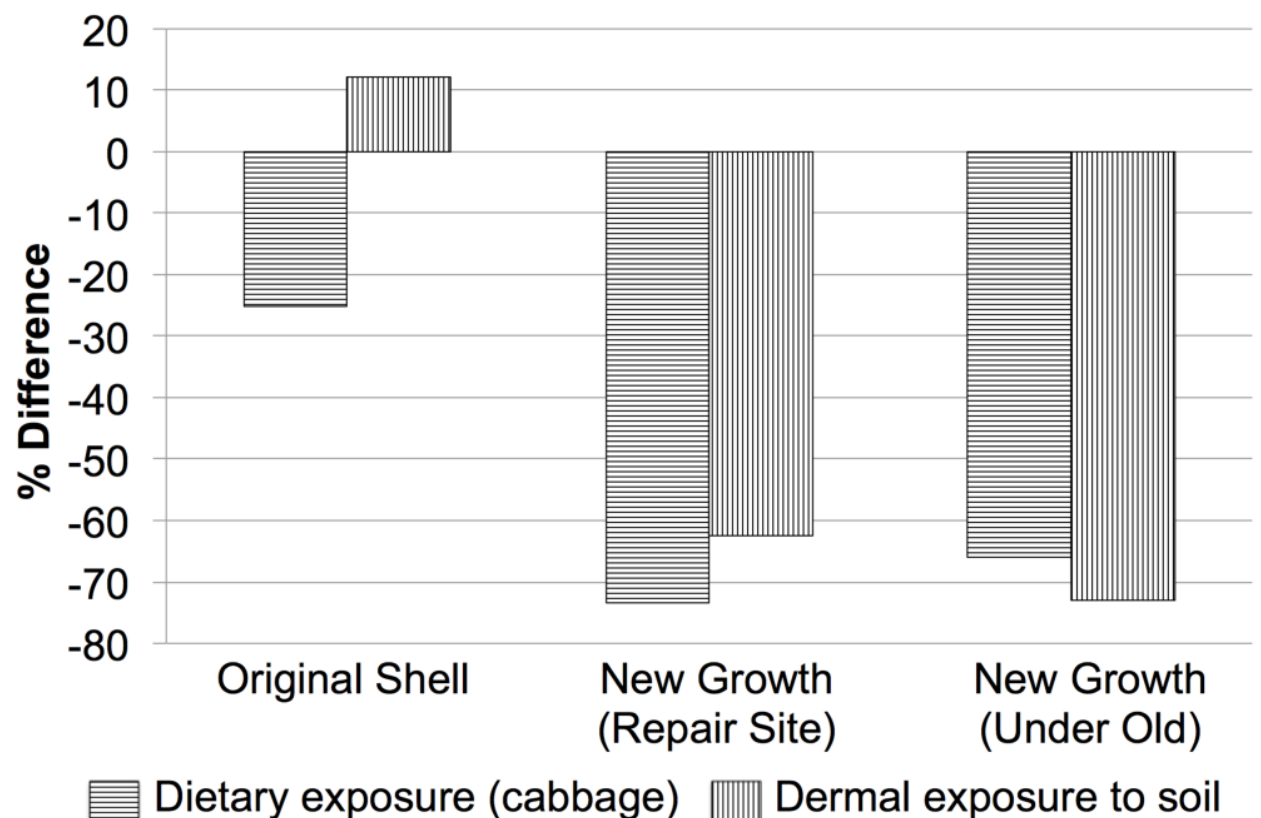

Figure 5. (a) Percent difference of the control average modulus between the dietary and dermal tungsten exposed samples (b) Percent difference of the control average hardness between the dietary and dermal tungsten exposed samples. 